\title{
Acoustic Absorption Characteristics of Porous Asphalt Containing Coconut Shells
}

\author{
Norhafizah Manap, Ramadhansyah Putra Jaya, Muhammad Nazri Borhan, Norhashidah \\ Manap, Juraidah Ahmad
}

\begin{abstract}
In this study, coconut shells were used as aggregate replacement in porous asphalt to observe its effect on sound absorption through Impedance Tube test. For coconut shells aggregate porous asphalt to be used in realistic situations it is essential to ensure its mix integrity, resistance to oxidation and raveling as well as its durability; therefore, the Cantabro Test, Binder drain-down test and Theoretical Maximum Density were also conducted in this study. The result showed that porous asphalt containing coconut shells exhibited significance improvement of sound absorption. The sound absorption coefficient of porous asphalt incorporating $10 \%, 30 \%$ and $50 \%$ of coconut shells approximately at the peak of the curve which is at the frequency of $850 \mathrm{hz}$ are $0.93,0.96$ and 0.93 while for conventional porous asphalt is 0.89 . This study also found that porous asphalt containing 10 - 50\% of coconut shells contributed a significance improvement in sound absorption compare than conventional porous asphalt at the frequency of $200-1600 \mathrm{~Hz}$. However, only porous asphalt containing $10 \%$ of coconut shells satisfied all the parameters tested similar to the conventional porous asphalt.
\end{abstract}

Keywords : Coconut shells, porous asphalt, sound absorption

\section{INTRODUCTION}

Sound acoustic absorption is one of porous asphalt characteristics that make porous asphalt unique and becoming a subject of many investigations. Porous asphalt pavement was developed with the purpose of preventing slippery roads that can cause traffic accidents. Its porous structure was additionally found to possess a sound absorbing effect that makes porous asphalt pavement useful for the reduction of traffic noise. In comparison to dense graded asphalt mixtures, a reduction of traffic noise at source by $3-5$ decibles an average can be achieved by porous asphalt [1]. Within the ongoing development of silent road surfaces, sound-absorbing porous road surfaces have been very

Revised Manuscript Received on November 05, 2019.

* Correspondence Author

Norhafizah Manap, Department of Civil and Structural Engineering, Faculty of Engineering and Built Environment, Universiti Kebangsaan Malaysia, Bangi, Malaysia

Ramadhansyah Putra Jaya*, Faculty of Civil Engineering Technology, Universiti Malaysia Pahang, Pahang, Malaysia

Muhammad Nazri Borhan, Department of Civil and Structural Engineering, Faculty of Engineering and Built Environment, Universiti Kebangsaan Malaysia, Bangi, Malaysia

Norhashidah Manap, Faculty of Mechanical Engineering, Universiti Teknologi MARA, Terengganu Branch Bukit Besi Campus, Dungun, Malaysia

Juraidah Ahmad, Faculty of Civil Engineering, Universiti Teknologi Mara, Shah Alam, Selangor, Malaysia effective when it comes to obtaining noise reduction.

This study investigates the sound absorption characteristics of porous asphalt concrete pavements containing Coconut shell using an impedance tube to assess noise reduction performance. Coconut shells (CS) is a biowaste product as others such as bamboo, jute, hemp, oil palm shell and rice husk have shown great potential as reinforcement in thermoplastics. These biowastes have contributed many environmental advantages such as low density, low cost, lower pollution, good thermal properties, high toughness, reduced tool wear and biodegradability over traditional reinforcing filler such as glass and carbon. Besides that, coconut shell also categories as Metal matrix composites (MMC) which can ameliorate characteristics such as great precise strength, precise modulus, good weather resistance and great damping capacity contrast to unreinforced alloys. CS also has high water absorption ability because of its open structure containing many hydroxyl and acetyl group hence hemicelluloses can partly soluble in water and hygroscopic [2]. Because of the characteristics of coconut shells, this study is conducted in determining the effect of porous asphalt containing CS in terms of sound absorption ability.

\section{MATERIALS AND EXPERIMENTAL PROCEDURES}

\section{A. Raw Materials Preparation}

The materials used in this study were including polymer modified bitumen with a performance grade of 76 , granite and also the utilization of coconut shell as replacement of granite by percentage. In this investigation, the CS was obtained in 50 to 100 millimetres with the fibre and coconut meat still attached. The coconut shells were then sun dried for 24 hours before the fibre and the meat were detached. After the cleaning process, the CS was being crushed either by using pestle or crushing machine to obtain the required size. The CS was then being sieved consistent with the specification [3] as shown in Fig. 1. The physical testing for aggregate and CS were also having been conducted in the purpose of determining the properties of CS and granite. The tests were including aggregate impact value test, sieve analysis, specific gravity and water absorption test.

\section{B. Mix Preparation and Test}

This study is considered four types of CS mixing proportions that were used as aggregate replacement, which

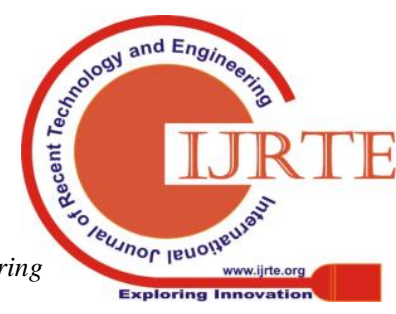


are $0 \% \mathrm{CS}$ (conventional porous asphalt), $10 \% \mathrm{CS}, 30 \% \mathrm{CS}$, and $50 \% \mathrm{CS}$. The replacement is involving coarse aggregates between size 5 to $20 \mathrm{~mm}$. Porous asphalt mixtures that consist of aggregate, binder and CS are mixed at $190 \pm 0.5^{\circ} \mathrm{C}$ and compacted at $180 \pm 0.5^{\circ} \mathrm{C}$. The mixes were compacted with 50 blows on each side by using the standard Marshall hammer. After compaction, the specimens were removed from the moulds and allowed to cool down. The performance of porous asphalt mix with CS were evaluated through percentage of air voids, binder drainage and abrasion loss. In addition, sound absorption of specimens is identified through the impedance tube test.

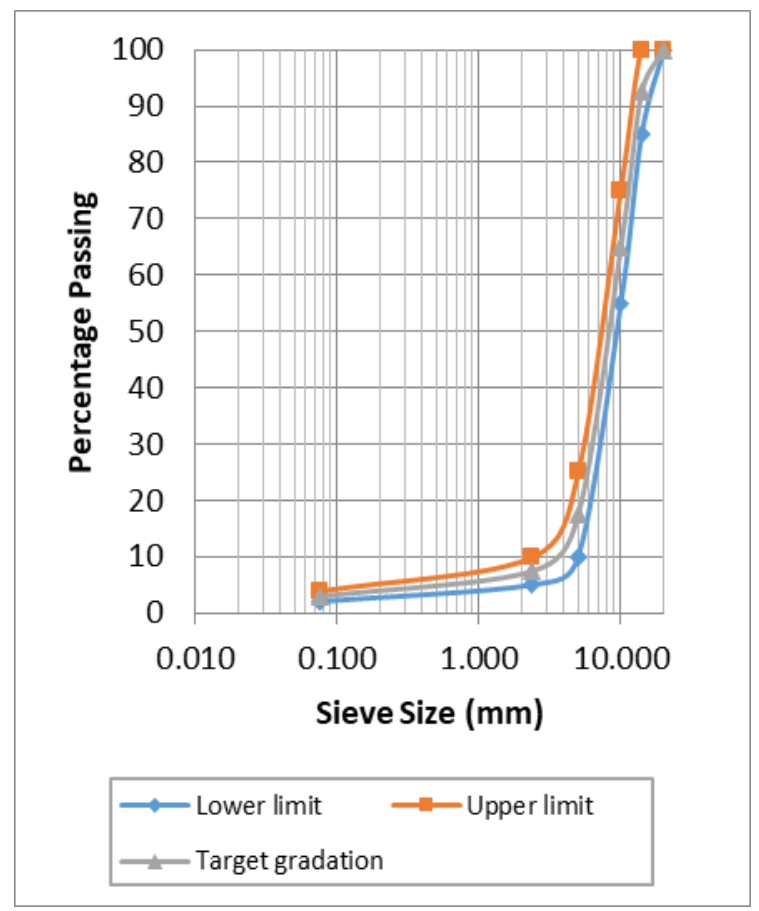

Fig.1: Gradation limit of porous asphalt grading B [3]

\section{Cantabro Test}

The Cantabro test is typically used for open graded asphalt mixtures [4] to measure the mixture resistance to stone loss at high frequency. Four Marshall Specimens that have been cooled and dried, the weight of each sample have been taken and then placed into the Los Angeles drum without abrasion loads (balls) with one sample at time. The drum is turned at a velocity between 188 and $208 \mathrm{rad} / \mathrm{s}$ and submitted to 300 revolutions. This procedure is repeated for the other specimens. The specimens after test were weight and the stone loss or attrition resistance is computed using the formula below;

$$
\mathrm{L}=(\mathrm{M} 0-\mathrm{M} 1) /(\mathrm{M} 0) \times 100[3]
$$

Where M0 is the weight of the specimen before place into Los Angeles drum and M1 is the weight of the specimen after test.

\section{Air Voids Requirements}

The design and in-place air voids shall be in the range of 18 to 25 percent [3]. Percentage of air voids is calculated by comparing a test specimen's bulk density with its theoretical maximum density and assuming the different is due to air [5]. The Standard Test Method for Percent Air voids in compacted dense and Open Bituminous Paving Mixtures [6] were conducted and percentage of air voids was calculated by using the formula below;

$\%$ Air Voids $=100(1-($ BRD/MRD $))[6]$

Where BRD is a bulk specific gravity and MRD is a theoretical maximum specific gravity and density.

\section{E. Binder Drain-Down Test}

Binder drain-down test were carried out in accordance with the test method as specified in Standard Test Method for Determination of Draindown Characteristics in Uncompacted Asphalt Mixtures [7]. The sample of prepared asphalt mixture which is placed in a wire basket and positioned on a plate was placed in an oven for one hour. Any drained materials from the asphalt was collected and determined. Drain down is considered to be that portion of material which separates itself from the sample as a whole and is deposited outside the wire basket during the test including either asphalt binder or a combination of asphalt binder, additives, or fine aggregates. The amount of drain down was calculated by using the formula below to the nearest $0.1 \%$;

Draindown $(\%)=(\mathrm{D}-\mathrm{C}) /(\mathrm{B}-\mathrm{A}) \times 100[7]$

Where A is a mass of the empty wire basket, $\mathrm{B}$ is a mass of the wire basket and sample, $\mathrm{C}$ is a mass of the empty catch plate or container, and D is a mass of the catch plate or container plus drained material.

\section{F. Impedance Tube Test}

Impedance Tube Test is to measure sound absorption coefficients of absorptive materials. This test was carried out in accordance with the Standard Test Method for impedance and Absorption of Acoustical materials using a tube, two microphones and a digital frequency Analysis System [8]. The acoustic properties of the porous asphalt containing CS and control samples were measured using a two-microphone transfer function method. It covers the use of an impedance tube, two microphone locations, and a digital frequency analysis system for determination of normal incidence sound absorption coefficient and normal specific acoustic impedance ratios of materials.

\section{RESULTS AND DISCUSSIONS}

\section{A. Aggregate Properties}

Based on Table-1 below, coconut shell indicate more strength compared to natural aggregates due to its aggregate impact value is only $5.7 \%$ while for natural aggregate is $28.4 \%$. It shows that coconut shell has ability to resist sudden shock or impact and this result agreed by Kukarni and Gaikward [9] in their study on the title of comparative study on coconut shell aggregate with conventional aggregate. However, the water absorption of CS is high which is $24 \%$ compared to natural aggregate which is only $0.5 \%$. This exhibit coconut shell has the ability to absorb more bitumen during mixing. Coconut shell also showed lower value of apparent and bulk specific gravity which is 1.440 and 1.070 while for natural aggregate is 2.635 and 2.600 respectively. Lower specific gravity of CS will also affect the density of mixing sample. 
Table-1: The properties of Coconut Shell and Natural Aggregate

\begin{tabular}{|c|c|c|}
\hline Properties & $\begin{array}{c}\text { Coconut } \\
\text { Shell }\end{array}$ & $\begin{array}{r}\text { Natural } \\
\text { Aggregate }\end{array}$ \\
\hline Aggregate Impact Value, \% & 5.7 & 28.4 \\
\hline Water absorption test, \% & 24.0 & 0.5 \\
\hline Apparent Specific Gravity & 1.440 & 2.635 \\
\hline Bulk Specific Gravity & 1.070 & 2.600 \\
\hline
\end{tabular}

\section{B. Loss of abrasion}

Table-2 displays the abrasion loss of porous asphalt at different percentage of CS content. The abrasion loss is expressed as the percentage of mass loss to the original mass. The resistance of compacted porous mixes coconut shell to abrasion loss is analyzed by means of the Cantabro test. The amount of abrasion loss indicates the inter-aggregate particle cohesion loss in the porous mixes tested. Standard specification for Road Works (JKR/SPJ/2008-S4) [3] required that the average abrasion loss of mass porous asphalt shall be not more than $15 \%$. From the result, the abrasion loss of mass for $0 \% \mathrm{CS}$ and $10 \% \mathrm{CS}$ are lower than $15 \%$. However, the result of $30 \% \mathrm{CS}$ and $50 \%$ CS exhibited a drop in abrasion resistance. It can be concluded that utilization of $\mathrm{CS}$ in higher quantities does not increase in resistance to abrasion. The lower the abrasion loss shows the less prone the mixtures to disintegrate [10].

Table-2: Abrasion Loss of porous asphalt containing coconut shells

\begin{tabular}{|c|c|c|}
\hline Types of Mix & Specification & Abrasion Loss, \% \\
\hline $0 \%$ CS & & 4.6 \\
\hline $10 \%$ CS & \multirow{2}{*}{$0-15 \%$} & 13.14 \\
\hline $30 \%$ CS & & 28.07 \\
\hline $50 \%$ CS & & 54.38 \\
\hline
\end{tabular}

\section{Air Voids}

Air voids content show the porosity of the mixture. It is desirable to drain water rapidly to prevent water ponding on the pavement surface. Higher air voids also affected the ability of sound absorption in porous asphalt. There should be enough pores on the surface of materials to allow the sound wave to enter the porous materials to facilitate the sound dissipation by friction [11]. On the contrary, higher air void may be subjected to raveling problem due to poor resistance to disintegration. Hence, the porosity must be carefully selected. From the result obtained, the air voids percentage is increasing with the increasing of CS content. It showed that linear relationship between both parameters. The air voids for $0 \%, 10 \%, 30 \%$ and $50 \%$ were $19.9 \%, 23.1 \%, 28.8 \%$ and $33.1 \%$ as shown in Table-3. The air voids are influenced by fines size aggregate. This presented that the more CS content the more air voids in mixtures. The acceptable level of air voids is below $25 \%$ as stated in Standard specification for Road Works (JKR/SPJ/2008-S4) [3], thus only 10\% CS content is in the range.

Table-3: Air voids of porous asphalt containing coconut shells

\begin{tabular}{|c|c|c|}
\hline Types of Mix & Specification & Air voids, \% \\
\hline 0\% CS & & 19.9 \\
\hline $10 \%$ CS & \multirow{2}{*}{$18-25 \%$} & 23.1 \\
\hline 30\% CS & & 28.8 \\
\hline $50 \%$ CS & & 33.1 \\
\hline
\end{tabular}

\section{Binder drain down}

The result illustrates in Table-4 shown that porous asphalt with $10 \% \mathrm{CS}$ replacement has the lower average binder drain down which is nearest to $0.10 \%$ followed by $0 \% \mathrm{CS}, 30 \% \mathrm{CS}$ and $50 \% \mathrm{CS}$ with binder drain $0.12 \%, 0.16 \%$ and $0.25 \%$, respectively. The result shown that all the samples were within the acceptable level. This test is primarily used for mixtures with high coarse aggregate content that internal voids of the uncompact mix are larger, resulting in more drain down such especially for open-graded friction course. Hence the use of $10 \% \mathrm{CS}$ is an exhibit better result than conventional mix that can benefit to alleviate the problem of binder drainage.

Table-4: Binder drain down of porous asphalt containing coconut shells

\begin{tabular}{|c|c|c|}
\hline Types of Mix & Specification & $\begin{array}{c}\text { Binder drain } \\
\text { down, \% }\end{array}$ \\
\hline $0 \%$ CS & & 0.12 \\
\hline $10 \%$ CS & \multirow{2}{*}{$<0.3 \%$} & 0.10 \\
\hline $30 \%$ CS & & 0.16 \\
\hline $50 \%$ CS & & 0.25 \\
\hline
\end{tabular}

\section{E. Sound absorption}

Table-5 shows the density and air voids of porous asphalt which is extracted from Cantabro test for each percentage while Table-6 and Fig. 2 represents the comparison of impedance tube test results of each CS content.

Table-5: Comparison of density and air voids of porous asphalt

\begin{tabular}{|c|c|c|}
\hline Type of Mix & Density (g/cm3) & Air Voids (\%) \\
\hline $\mathbf{0 \%}$ CS & 1.957 & $19.90 \%$ \\
\hline $\mathbf{1 0 \%}$ CS & 1.769 & $23.077 \%$ \\
\hline $\mathbf{3 0 \%}$ CS & 1.488 & $28.76 \%$ \\
\hline $\mathbf{5 0 \%}$ CS & 1.254 & $33.07 \%$ \\
\hline
\end{tabular}

It is clearly shown in Fig. 2 that an improvement attenuation of sound wave energy is achieved by the increasing of CS content, based on measurements of sound absorption coefficients. The $10 \%$ of replacement shows the best replacement of coconut shells. The sound absorption coefficient approximately at the peak of the curve which is at the frequency of $850 \mathrm{hz}$ for porous asphalt incorporating $10 \%$, $30 \%$ and $50 \%$ were $0.93,0.96$ and 0.93 while the conventional porous asphalt $(0 \%)$ is 0.89 . The sound absorption coefficient $(\alpha)$ at 100 to $700 \mathrm{~Hz}$ for $10 \% \mathrm{CS}$ is between 0.04 to $0.57,30 \% \mathrm{CS}$ is 0.06 to $0.56,50 \% \mathrm{CS}$ is $0.06-0.62$ while for conventional porous asphalt is 0.06 to 0.52 . The frequencies located between 700 to $1000 \mathrm{~Hz}$, with a maximum peak at $850 \mathrm{~Hz}$ for porous asphalt containing $10 \%$, $30 \% \mathrm{CS}$ is within 0.57 to $0.64,30 \%$ is 0.56 to $0.69,50 \% \mathrm{CS}$ is 0.62 to 0.67 and $0 \%$ is 0.52 to 0.63 . Lastly, the third frequencies peak is observed between 1000 and $1600 \mathrm{~Hz}$, with a coefficient absorption in range of 0.64 to 0.19 for $10 \%$ CS, 0.69 to 0.19 for $30 \%$ CS, 0.67 to 0.23 for $50 \%$ and 0.63 to 0.19 for conventional asphalt. Bert Peeters et al. [12] stated in his study that it is important to tune the sound absorption frequencies to the noise spectrum emitted by the road vehicles. He also stated that sound absorption for passenger car should occur around $800-1000 \mathrm{~Hz}$ while for truck around 600-800 Hz. 
The sound absorption coefficient for $600-800 \mathrm{~Hz}$ for $0 \%$, $10 \%, 30 \%$ and $50 \%$ are 0.27 to $0.84,0.3$ to $0.88,0.29$ to 0.90 and 0.34 to 0.90 while for $800-1000 \mathrm{~Hz}$ are 0.84 to $0.63,0.88$ to $0.64,0.90$ to 0.69 and 0.90 to 0.67 . From the results, clearly shows that, porous asphalt wit CS contain exhibited provide and improvement in acoustic absorption. It is also found that, the porous asphalt with lower density and higher air voids exhibit higher sound absorption. Based on the finding, the $10 \%$ CS content porous asphalt provide the best performance in term of mix integrity, durability, resistance to oxidation and raveling as well acoustic absorption characteristic compared to other CS content. Porous asphalt with $10 \%$ CS content also shows a significance improvement in sound absorption.

Table-6: Acoustic absorption coefficient of porous asphalt with different CS content

\begin{tabular}{|c|c|c|c|c|}
\hline \\
\hline Frequency $(\mathrm{Hz})$ & $0 \% \mathrm{CS}$ & $10 \% \mathrm{CS}$ & $30 \% \mathrm{CS}$ & $50 \% \mathrm{CS}$ \\
\hline 100 & 0.0596 & 0.0413 & 0.0589 & 0.0643 \\
\hline 150 & 0.0256 & 0.0230 & 0.0310 & 0.0381 \\
\hline 200 & 0.0326 & 0.0358 & 0.0387 & 0.0417 \\
\hline 250 & 0.0404 & 0.0460 & 0.0475 & 0.0507 \\
\hline 300 & 0.0509 & 0.0576 & 0.0582 & 0.0632 \\
\hline 350 & 0.0639 & 0.0717 & 0.0718 & 0.0797 \\
\hline 400 & 0.0812 & 0.0905 & 0.0901 & 0.1021 \\
\hline 450 & 0.1055 & 0.1171 & 0.1163 & 0.1331 \\
\hline 500 & 0.1416 & 0.1573 & 0.1573 & 0.1787 \\
\hline 550 & 0.1924 & 0.2137 & 0.2132 & 0.2435 \\
\hline 600 & 0.2666 & 0.2961 & 0.2923 & 0.3357 \\
\hline 650 & 0.3738 & 0.4133 & 0.4052 & 0.4630 \\
\hline 700 & 0.5195 & 0.5668 & 0.5598 & 0.6227 \\
\hline 750 & 0.6902 & 0.7390 & 0.7407 & 0.7846 \\
\hline 800 & 0.8364 & 0.8795 & 0.8968 & 0.8979 \\
\hline 850 & 0.8932 & 0.9299 & 0.9649 & 0.9281 \\
\hline 900 & 0.8521 & 0.8804 & 0.9285 & 0.8794 \\
\hline 950 & 0.7486 & 0.7698 & 0.8218 & 0.7824 \\
\hline 1000 & 0.6296 & 0.6435 & 0.6923 & 0.6698 \\
\hline 1050 & 0.5240 & 0.5329 & 0.5739 & 0.5688 \\
\hline 1100 & 0.4391 & 0.4454 & 0.4777 & 0.4871 \\
\hline 1150 & 0.3738 & 0.3785 & 0.4034 & 0.4248 \\
\hline 1200 & 0.3246 & 0.3267 & 0.3472 & 0.3721 \\
\hline 1250 & 0.2862 & 0.2869 & 0.3044 & 0.3275 \\
\hline 1300 & 0.2557 & 0.2569 & 0.2701 & 0.2952 \\
\hline 1350 & 0.2325 & 0.2334 & 0.2435 & 0.2714 \\
\hline 1400 & 0.2152 & 0.2173 & 0.2245 & 0.2507 \\
\hline 1450 & 0.2028 & 0.2094 & 0.2130 & 0.2375 \\
\hline 1500 & 0.1918 & 0.2046 & 0.2048 & 0.2271 \\
\hline 1550 & 0.1868 & 0.1968 & 0.1981 & 0.2206 \\
\hline 1600 & 0.1885 & 0.1884 & 0.1943 & 0.2257 \\
\hline
\end{tabular}




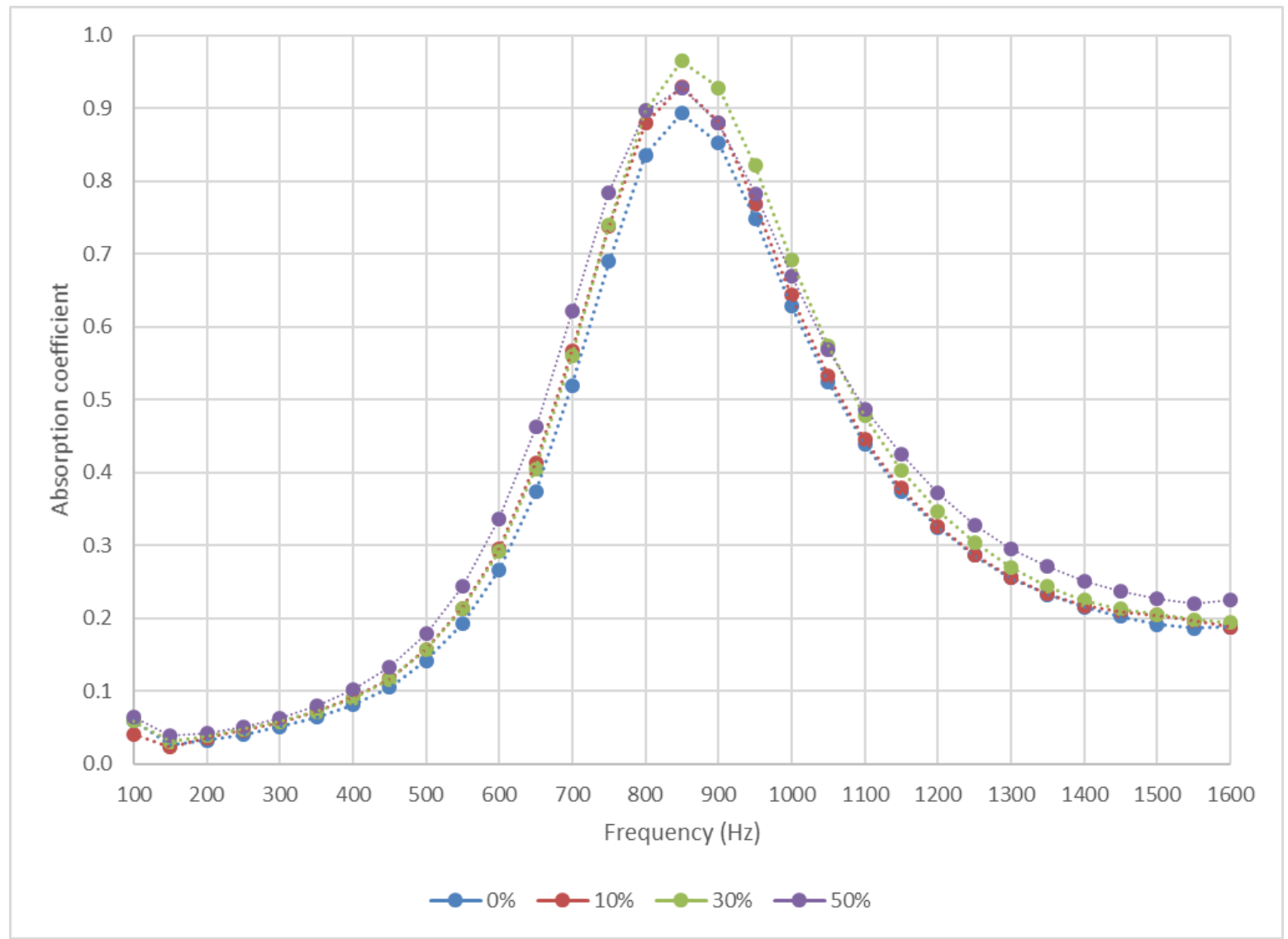

Fig. 2. Correlation between absorption coefficient and frequency

\section{CONCLUSION}

The results clearly indicate that the use of CS as coarse aggregates replacement in porous asphalt provides additional improvements in sound absorption. The replacement of $10 \%$ CS can be satisfactorily used as an aggregate replacement material of porous asphalt concrete. However, the replacement of CS more than $10 \%$ exhibits no significant improvement in air voids and loss of abrasion. Thus the optimum replacement of CS in porous asphalt is $10 \%$.

\section{ACKNOWLEDGMENT}

The support provided by the Malaysian Ministry of Higher Education and Universiti Malaysia Pahang in the form of a research grant (RDU/UMP) vote number RDU1803160 for this study is highly appreciated.

\section{REFERENCES}

1. Ponniah J.,Tabib S., Lane B. and Raymond C., 2010. Evaluation of the Effectiveness of Different Mix Types to Reduce Noise Level at the Tire/Pavement Interface. Advances in Pavement Design and Construction Session of 2010 Annual Conference of the Transportation Association of Canada in Halifax, Nova Scotia. Retrieved

from:http://conf.tac-atc.ca/english/resourcecentre/readingroom/con ference/conf2010/docs/i3/ponniah.pdf

2. Lay Ting, T., Putra Jaya, R., Abdul Hassan, N., Yaacob, H., Sri Jayanti, D. and Ariffin M.A. 2015. A Review of Chemical and Physical properties of Coconut Shell in Asphalt Mixtures. Jurnal Teknologi. 78:4 (2016) 85-89.

3. JKR: Standard and specification for road works, Section 4-Flexible pavement (JKR/SPJ/2008-S4), Malaysia (2008).
4. J. D. Doyle and I. L. Howard. 2011. Evaluation of the Cantabro Durability Test for Dense Graded Asphalt. Geo-Frontiers Congress 2011. 4563-4572. Dallas, Texas : ASCE Library

5. Pavement Interactive. 2012. Retrieved from Theoretical Maximum Specific Gravity: http://www.pavementinteractive.org/theoretical-maximum-specific-g ravity/.

6. ASTM D3203-05. 2005. Standard Test Method for Percent Air Voids in Compacted Dense and Open Bituminous Paving Mixtures. Annua Book of ASTM Standards, West Conshohocken, Philadelphia, U.S.A

7. ASTM D6390-11. 2011. Standard Test Method for Determination of Draindown Characteristics in uncompacted Asphalt mixtures. Annual Book of ASTM Standards, West Conshohocken, Philadelphia, U.S.A.

8. ASTM E1050-12. 2012. Standard Test Method for Impedance and Absorption of Acoustical materials using a Tube, Two Microphones and a Digital Frequency Analysis System. Annual Book of ASTM Standards, West Conshohocken, Philadelphia, U.S.A. Kimura S. Journal Paper Title, J. of Computer Science, Vol. 1, Issue 2, 1987, pp. 23-49.

9. Kukarni V. P \& Gaikwad S. K. B. 2013. Comparative Study on Coconut Shell Aggregate with Conventional Concrete. International Journal of Engineering and Innovative Technology (IJEIT). 2(12).

10. Ahammed M. A. and Tighe S. L. 2011. Acoustics Absorption of Coventional Pavements. International Journal of Pavement Research and Technology. 4(1): 41-47.

11. Seddeq, H.S. 2009.Factors Influencing Acoustic Performance of Sound Absorptive Materials. Australian Journal of Basic and Applied Science. 3(4):4610-4617.

12. Peeters B., Michel H. and Kuijpers. A. 2016. Influence of Pore Structure on Sound Absorption in Porous Road Surfaces. 42 Anniversary for Acoustics. Retrieved from website http://webcache.googleusercontent.com/search?q=cache:V0IDGAfrq UQJ:www.mplusp.eu/publicatie/influence-pore-structure-sound-abs orption-porous-road-surfaces $+\& \mathrm{~cd}=1 \& \mathrm{hl}=\mathrm{en} \& \mathrm{ct}=\mathrm{clnk}$

Published By:

Blue Eyes Intelligence Engineering 